\title{
I CONGRESO NACIONAL DEL PARTIDO DEMOCRATA POPULAR
}

Durante los días 25 y 26 de septiembre de 1982 se celebró en el Palacio de Exposiciones y Congresos de Madrid el I Congreso Nacional del Partido Demócrata Popular. Con la asistencia de mil compromisarios provinciales, el Congreso constituyente del PDP profundizaba en la línea marcada por la Convención Nacional celebrada el 30 de julio, estructurándose en torno a tres núcleos básicos: el informe sobre la situación política de España, pronunciado por el virtual presidente del partido, Oscar Alzaga Villaamil; el estudio de ponencias en Comisiones y Pleno, y, por último, la elección de los órganos directivos del partido.

\section{INFORME SOBRE LA SITUACION POLITICA}

El informe que abría el Congreso partía de la conciencia de la crisis política del país - debilidad de la acción de Gobierno, crisis del sistema de partidos políti$\cos \mathrm{y}$, como corolario de lo anterior, crisis de ilusión colectiva-, para, tras analizar los puntos álgidos de la misma y señalar el fin del mapa político de la transición, apuntar alternativas concretas de cara a la confrontación electoral del 28 de octubre.

Frente a la política de consenso UCD-PSOE y a su furor nomocrático, incidía ya inicialmente la intervención de Oscar Alzaga sobre la necesidad de una política con finalidades y principios nítidos, «una política de Gobierno acertada y mantenida tenazmente día a día» capaz de hacer frente operativamente a los grandes problemas nacionales: economía, orden público y consolidación de las instituciones democráticas; una democracia «netamente más firme», en definitiva, que, junto a una mayor profundización en las libertades reales, garantizase el contenido de legitimidad por la eficacia (Max Weber) necesario para contribuir decididamente a la legitimación del sistema entre el pueblo español.

Junto a la urgencia de un Gobierno con capacidad para acelerar la puesta en práctica del plan energético, incentivar fiscalmente el ahorro, incrementar nuestra competividad en los mercados exteriores, aplicar una rigurosa política de austeridad nacional, logrando a la par una mayor eficacia administrativa en todo lo que concierne a la vida económica y un Estado capaz de garantizar sin oquedades el monopolio del poder legítimo, abogaría el ponente por una «política de principios» susceptible de sustituir la política de oportunismos y la ficticia identificación entre el Estado y la sociedad característicos del entonces partido del Gobierno por la «humilde pero trascendente tarea de ósmosis y endómosis entre la sociedad y las instituciones 
políticas». De acuerdo con el análisis de Alzaga, el aglutinamiento del amplio espectro sociopolítico que fuera artífice de una reforma democrática sin ruptura revolucionaria en un partido único superaba, por una parte, el esquema de partidos europeos, al englobar elementos liberales, democristianos y socialdemócratas, amén de otros núcleos de difícil homologación con los parámetros europeos, y, por otra, se relevaba tras el período constituyente como inviable, al no ser compartido el programa electoral del 79 por muchos dirigentes y parlamentarios centristas. La solución pragmática en el seno de la UCD optaba, ante la imposibilidad de llevar a la práctica el programa electoral, por una ambigüedad superlativa que conduciría en breve plazo a la expulsión de la contienda política de todos los valores con solidez suficiente para ofrecer un firme punto de apoyo a la opinión pública y, en consecuencia, a un hipereclecticismo con ribetes de improvisación permanente, ambigüedades y eclecticismos que llevarían a que la UCD, «como la guitarra del mesón del poema de Machado, suena hoy jota y mañana petenera o improvisa por su cuenta, en el mejor de los casos, una especie de ecléctica y neutralizada combinación de jota y de petenera que busca adaptarse al gusto medio de los militantes residuales centristas, a la vez que se alejan sin disimulo los oídos de los electores». Así, el capítulo fulgor y ocaso del centro político en España es, en el análisis de Oscar Álzaga, el resultado del progresivo alejamiento de sus electores, con el subsiguiente anquilosamiento y petrificación de la UCD hasta perder toda conexión íntima con la España vital. Un capítulo que hoy, tras las elecciones del 28 de octubre, ya pertenece a la historia, pero imprescindible tanto para comprender el presente como las raíces de un análisis que se ha revelado como certero.

De este modo, la declaración de obsolescencia del mapa político diseñado en la transición es al mismo tiempo el acta de constitución de «un partido popular inspirado en el humanismo cristiano», concebido como «vehículo político más idóneo para la comunicación del sentir de las clases medias y populares españolas». $Y$ es a partir de aquí, a partir de la necesidad de contribuir a la integración de amplios sectores de las clases medias en el sistema democrático - «afectando, en consecuencia, a su consolidación»-, donde el informe sobre la situación política aborda la coalición electoral con Alianza Popular, una coalición susceptible de irse configurando -en palabras del ponente- como la gran fuerza política que contrapese la del partido socialista sobre la base de un «escrupuloso respeto» a la propia identidad del PDP.

Definida por los valores de un humanismo integral que «desmitifique la vieja fe en el Estado paternalista» y por «la posibilidad de enriquecer cualitativamente la sociedad española», es esta misma identidad ideológica la que en la última parte del informe delimita el marco teórico para una crítica de la idea de cambio - «a estas alturas resulta pueril propugnar el cambio por el cambio como sinónimo de progreso"- y de puntos concretos del programa del PSOE, concluyendo así la intervención de Oscar Alzaga, quien en la sesión del domingo sería elegido presidente del partido.

\section{LAS COORDENADAS IDEOLOGICAS DEL PARTIDO DEMOCRATA POPULAR}

A continuación entresacamos de las ponencias debatidas y aprobadas en el Congreso los puntos definitorios de la naturaleza y estrategia políticas del PDP.

- El PDP se define como un partido popular que encuentra sus raíces ideológicas en el humanismo de inspiración cristiana. Si bien del cristianismo no se deriva ningún programa político determinado, su concepción del hombre brinda una base ética para una política responsable: en este sentido el PDP se concibe como un partido netamente aconfesional. 
El progreso es fruto del trabajo dignificador del hombre, pero no es un valor absoluto. El PDP es un partido de progreso y renovación de la sociedad cuya tarea política consiste en proteger lo que ha demostrado ser útil para la sociedad y en desarrollar nuevas propuestas de acción política para así llevar a cabo el desarrollo. social, económico y cultural de España en libertad.

- Los valores fundamentales que propugna el PDP son: libertad, solidaridad, justicia y trabajo. La libertad es inseparable del progresivo avance de la justicia social; en especial, la libertad de empresa implica graves responsabilidades sociales respecto a los que en ella participan, a su entorno y a la comunidad en general. La solidaridad es la expresión de la naturaleza social del ser humano y une no sólo a grupos con intereses legítimos, sino que, superando los intereses en conflicto, obliga a los más poderosos a intervenir a favor de los más débiles y a todos en favor del bienestar general. Justicia significa igualdad de derechos para todos; la igualdad de oportunidades es el complemento indispensable de la igualdad ante la ley. La configuración de una sociedad en libertad exige el respeto al principio de subsidiariedad.

- El trabajo es una fuente insustituible de dignificación y realización integral de la persona. Por eso, la justicia y la solidaridad en. la vida laboral exigen el pleno empleo. En la vida laboral, al igual que en todas las actividades sociales, el trabajador debe tener la posibilidad de participar en la configuración de su entorno, de intervenir en las decisiones.

- Le es connatural al PDP la vocación europea e iberoamericana del pueblo español. El PDP ha surgido en su mismo origen con una clara tendencia de homologación con los partidos europeos y americanos de raigambre demócrata cristiana y un profundo deseo de cohesionar esfuerzos por el bien común y de proyectarlos. hacia grandes empresas colectivas. La integración de España en Europa a todos los niveles (incluyendo la integración en la OTAN) y la potenciación de una auténtica Comunidad Iberoamericana de Naciones se definen como objetivos básicos de la política exterior española.

- Los rasgos diferenciales de una política económica colierente con el humanismo cristiano comprenden: mantener la actividad económica en el orden que le es propio, el orden privado, lo que no excluye la intervención del Gobierno ni la planificación indicativa y democrática; una política económica activa en la que al Gobierno le compete crear, estimular y corregir las condiciones que favorecen la eficacia de la actividad económica privada y el ejercicio de la solidaridad; la no utilización de medidas de tipo «paternalista»; por último, una actitud pragmática ante las doctrinas económicas. En definitiva, un orden económico identificado con la «economía social de mercado».

- Los objetivos de la política económica han de tender al fomento y protección de la iniciativa privada, del aumento en la calidad y cantidad del esfuerzo productivo, del ahorro, y a situar el beneficio en la posición de bien social que le corresponde. Para ello se articulan como objetivos instrumentales: el incremento de la inversión pública y privada, el aumento de la productividad y de la competividad, el desarrollo de las exportaciones, la contención de la inflación por debajo, al menos, de los dos dígitos.

- Las orientaciones concretas de la política económica incluyen una política de «oferta», el establecimiento de la economía de mercado, la contención del déficit del gasto público, la reorientación de la política fiscal en favor de la fámilia y la autofinanciación de las empresas, la remodelación de una política monetaria independiente de las «necesidades políticas» del Gobierno, la expansión de las inversiones públicas que demanden gran cantidad de mano de obra y/o induzcan una fuerte activación del sistema productivo general, el apoyo a las exportaciones, el fomento y protección de la pequeña y mediana empresa, una investigación tecnológica selec- 
tiva, el fortalecimiento de las cooperativas y la armonización de los intereses económicos en litigio mediante el análisis, la negociación y la concertación a medio plazo.

- Como medidas concretas de orden fiscal que se patrocinan están: revisión del mínimo exento del IRPF, actualizar las escalas de gravámenes de acuerdo con la evolución de la inflación, las rentas ahorradas e invertidas en actividades productivas no han de ser incluidas en la base del gravamen, revisar el tratamiento fiscal de la unidad familiar, aumentar el límite actual de las deducciones actuales por seguros de vida, desgravación de los beneficios aplicados a inversiones productivas en el impuesto sobre la renta de sociedades, actualización de activos y pasivos empresariales para que sólo tributen los beneficios reales, revisión a fondo del impuesto sobre el patrimonio y del trato fiscal de las plusvalías nominales, implantación del IVA en paralelo con reducciones de las cotizaciones empresariales a la Seguridad Social, elaboración de un nuevo proyecto de Ley del Impuesto sobre Sucesiones y Donaciones, armonización fiscal unitaria en todo el territorio nacional.

- EI PDP expresa su pleno apoyo al Estado de las autonomías; su desarrollo ha de realizarse teniendo en cuenta los siguientes parámetros: unidad de España; reconocimiento del derecho a la autonomía, con la consiguiente superación de su interpretación meramente tecnocrática; solidaridad interregional sobre la base del Fondo de Compensación Interterritorial; la racionalización del proceso autonómico sin reforma del título VIII de la Constitución ni LOAPA, en cuanto que esta última constituye un error político de extraordinaria gravedad; evitar que la transferencia de competencias a las Comunidades Autónomas produzca una duplicación del aparato burocrático existente; el mantenimiento de la unidad de mercado; la aceptación plena del carácter bilingüe de determinadas zonas del territorio nacional; el respeto a la autonomía de las Diputaciones Provinciales para la gestión de los intereses provinciales.

- El PDP se propone como objetivo fundamental el lograr un sistema educativo realmente democrático acorde, por tanto, con las exigencias que imponen la libertad y la justicia, cuyas pautas orientativas son: el pluralismo educativo, admitiendo la escuela intrapluralista (el pluralismo en la escuela) para quienes opten por esta experiencia pedagógica, y al mismo tiempo la existencia de centros internamente homogéneos (la pluralidad de escuelas); escolarización plena y libertad de enseñanza; la necesidad de una justa ley de financiación que haga efectiva la gratuidad de la obligatoria y un sistema de ayudas económicas suficientes para todos aquellos que quieran seguir estudios en los niveles no obligatorios, atendiendo a sus aptitudes y situación económica; una democratización educativa que suponga la relación participativa de todos los integrantes de la comunidad escolar y un juego dinámico de controles que distinga entre las funciones de gobierno y las de representación.

- La familia se define como el elemento natural y fundamental de la sociedad: deben facilitársele los cauces de representación y expresión adecuados en la vida pública; debe desarrollarse de inmediato el artículo 39 de la Constitución, dictándose una ley general de la familia; debe respetarse el derecho de los padres a escoger el tipo de educación que quieran para sus hijos; toda madre y su hijo, desde el momento de la concepción, tendrán derecho a la protección del Estado y a la asistencia sanitaria durante el embarazo, el parto y el período posterior al mismo; se establecerá un régimen especial de la Seguridad Social del ama de casa; fiscalmente, la familia no debe ser perjudicada por el trabajo de ambos cónyuges; debe favorecerse el ahorro familiar, y los impuestos para la adquisición de vivienda, sobre herencia, donaciones, fundaciones, etc., que favorezcan a la familia deben estudiarse en este contexto. 
ELECCION DE CARGOS DIRECTIVOS DEL PARTIDO DEMOCRATA POPULAR

En la sesión plenaria del domingo fueron elegidos los siguientes cargos directivos del PDP: Oscar Alzaga, presidente; Eduardo Carriles, vicepresidente primero; José Luis Alvarez, vicepresidente segundo; José Manuel Otero Novas, secretario general; José Ramón Pin, vicesecretario general. EI Congreso se cerró con los discursos de clausura de Oscar Alzaga, Eduardo Carriles, José Luis Alvarez y José Manuel Otero Novas.

José María Beneyto 